\title{
The diagnostic value of CRP, IL-8, PCT, and STREM-1 in the detection of bacterial infections in pediatric oncology patients with febrile neutropenia
}

\author{
Karin G. E. Miedema • Eveline S. J. M. de Bont • Rob F. M. Oude Elferink • \\ Michel J. van Vliet • Claudi S. M. Oude Nijhuis • Willem A. Kamps • Wim J. E. Tissing
}

Received: 28 April 2010 /Accepted: 16 August 2010 /Published online: 28 August 2010

(C) The Author(s) 2010. This article is published with open access at Springerlink.com

\begin{abstract}
Purpose In this study, we evaluated C-reactive protein (CRP), interleukin (IL)-8, procalcitonin (PCT), and soluble triggering receptor expressed on myeloid cells-1 (sTREM1) as predictors for bacterial infection in febrile neutropenia, plus their usefulness in febrile neutropenia during chemotherapy-induced gastrointestinal mucositis.

Methods Plasma was obtained from pediatric oncology patients at presentation with febrile neutropenia $(n=43)$ and 24-48 h later $(n=17)$. The patients were classified as having or not having a bacterial infection. Plasma was also obtained of patients in the absence and in the presence of mucositis $(n=26)$.

Results At presentation with febrile neutropenia, median IL-8 and PCT levels were significantly increased in patients with a bacterial infection, in contrast to CRP and sTREM-1. IL-8 was the most sensitive marker for the early detection of bacterial infection, in combination with clinical parameters or PCT the sensitivity reached $100 \%$. After $24-48 \mathrm{~h}$, only PCT was significantly elevated during bacterial infection. IL-8 levels were significantly increased during mucositis. Mucositis did not cause considerable changes in PCT levels.
\end{abstract}

K. G. E. Miedema $(\bowtie) \cdot$ E. S. J. M. de Bont • M. J. van Vliet C. S. M. O. Nijhuis • W. A. Kamps • W. J. E. Tissing ( $\square)$ Division of Pediatric Oncology and Pediatric Hematology, Beatrix Children's Hospital, University Medical Center Groningen, University of Groningen,

PO Box 30.001, 9700 RB Groningen, The Netherlands e-mail: k.g.e.miedema@bkk.umcg.nl

e-mail: w.j.e.tissing@bkk.umcg.nl

R. F. M. O. Elferink

Department of Clinical Chemistry and Hematology,

Martini Hospital/Lab Noord,

Groningen, The Netherlands
Conclusions IL-8 is the most useful marker for the early detection of bacterial infections, compared with CRP, PCT, and STREM-1. IL-8 in combination with clinical parameters or PCT might be even more useful. Gastrointestinal mucositis alone does not affect PCT levels, in contrast to IL-8 levels, and therefore, PCT might be more useful for the detection of bacterial infections during mucositis than IL-8.

Keywords Febrile neutropenia $\cdot$ Bacterial infection . Biomarkers · Children · Mucositis

\section{Introduction}

Infectious complications in pediatric oncology patients are a major cause of morbidity and mortality. The risk of infections is particularly high during neutropenia, which is defined as an absolute neutrophil count (ANC) less than $0.5 \times 10^{9} / \mathrm{L}$ [1]. Fever during chemotherapy-induced neutropenia may be the first and only sign of bacterial infection, especially in children [2]. Therefore, standard care for patients with febrile neutropenia consists of routine hospitalization and empirical treatment with intravenous broad-spectrum antibiotics. Guidelines recommend that patients should not be discharged until they are afebrile for at least $24 \mathrm{~h}$ and the ANC has recovered [3]. However, in only $20-30 \%$ of the children an actual bacterial infection is documented during febrile neutropenia [2, 4-6]. In the majority of patients, fever has other causes, like viral or fungal infections, the malignancy itself, mucositis, drugs, or transfusions of blood products; all causes that do not require antibiotics. Yet there is no generally accepted method which can rapidly differentiate between patients with febrile neutropenia who are at high risk for bacterial 
infection, thus needing antibiotics, and in whom antibiotics can be withheld.

In the past decades, there have been many studies examining risk factors to assess the risk of having bacteremia or a severe bacterial infection during febrile neutropenia, such as indwelling central venous catheters, relapsed malignancy, comorbidity, hypotension, and several biomarkers [7-12]. The most widely used biomarker as diagnostic indicator is C-reactive protein (CRP). Unfortunately, CRP levels do not increase significantly until $24-48 \mathrm{~h}$ after onset of inflammation, and its specificity and positive predictive value are low [13-15].

Another inflammatory marker is interleukin 8 (IL-8). IL-8 is a cytokine with powerful chemotactic activity for neutrophils. IL-8 is released from monocytes, endothelial cells, and many other cells, in response to interleukin 1 (IL-1), tumor necrosis factor (TNF), and lipopolysaccharide (LPS) [16]. IL-8 levels have been shown to increase much earlier than CRP levels - increasing levels of IL-8 can frequently be detected even before onset of fever [17, 18]. Furthermore, we have shown previously in a group of pediatric and adult patients that withholding antibiotics in low-risk patients, which is defined by IL- 8 in combination with clinical parameters, is feasible [4].

Procalcitonin (PCT) was described as a new and innovative marker for infection for the first time in 1993 [19]. Inducers of PCT are bacterial endotoxins and exotoxins, as well as inflammatory cytokines, e.g., TNF, IL-2, and IL-6 [20]. During bacterial infections, levels of PCT reach plateau values within $8-24 \mathrm{~h}[21,22]$. It was recently suggested that monitoring PCT levels could be a valuable tool for guiding antibiotic treatment in nonneutropenic patients in an intensive care unit [23].

A recently discovered inflammatory marker is the soluble triggering receptor expressed on myeloid cells-1 (sTREM-1). sTREM-1 has been identified on neutrophils, mature monocytes, and macrophages, and is upregulated by LPS, bacteria, and fungi [24]. The predictive value of sTREM-1 for the presence of bacterial infections is questionable [25-28]. sTREM-1 has not been studied in neutropenic patients before.

Despite the fact that CRP is currently widely used as marker for bacterial infection, it has several major disadvantages, such as its delayed increase and low specificity. However, IL-8, PCT, and sTREM-1 have not been characterized well enough to know whether they could replace or supplement the use of CRP, or whether they can be of use in determining patients in whom antibiotics can be withheld or stopped early. Therefore, in this study we examined CRP, IL-8, PCT, and sTREM-1, separately and in combination, as early and late detectors for bacterial infection in pediatric oncology patients with febrile neutropenia.
In addition, we examined the markers during chemotherapyinduced mucositis, an inflammatory process of the gastrointestinal tract. Mucositis can be complicated by bacterial infections, e.g. Streptococcus viridans bacteremia or Clostridium difficile enterocolitis, but in most cases, mucositis only exists of an inflammatory component. Like bacterial infections, inflammatory mucositis can also cause fever, but does not require antibiotic treatment. Therefore, it is imperative to determine whether CRP, IL-8, PCT, and sTREM-1 can distinguish fever caused by mucositis from fever caused by bacterial infections.

\section{Methods}

Patient characteristics

Febrile neutropenia All pediatric oncology patients treated with chemotherapy from April 1999 to August 2002 at the Department of Pediatric Oncology and Haematology at the University Medical Centre of Groningen, the Netherlands, were asked to participate in a prospective study on febrile neutropenia [4]. Clinical data were collected of all patients from their patient charts. Neutropenia was defined as ANC less than $0.5 \times 10^{9} / \mathrm{L}$ and/or leukocytes less than $1.0 \times 10^{9} / \mathrm{L}$. Fever was defined as a single body temperature reading higher than $38.5^{\circ} \mathrm{C}$, or two or more recordings of a body temperature higher than $38.0^{\circ} \mathrm{C}$ during a 6 -h period.

Plasma was collected during each febrile neutropenic episode at presentation with febrile neutropenia, and after 24-48 h. Patients were divided into two groups, with or without bacterial infection/clinical sepsis. Bacterial infection was proven or suspected, as defined by either the growth of a known pathogen from culture of fluid collected from an otherwise sterile site, radiologically confirmed pneumonia or sinusitis, or abnormal vital signs suggesting clinical sepsis, e.g., hypotension or tachycardia and tachypnea ('abnormal' defined as more than two standard deviations above or below normal, corrected for age and sex).

Mucositis Mucositis was studied using blood samples drawn in a former study of pediatric patients newly diagnosed with acute myeloid leukemia at the University Medical Centre of Groningen between October 2005 and October 2006 [29], who were receiving chemotherapy likely to cause mucositis. Plasma was collected at two time points. The first sample was collected at the start of chemotherapy (range, $-1-5$ days), before developing mucositis. The second sample was collected at day 12 of chemotherapy (range, 7-17 days) during periods of chemotherapy-induced mucositis. Mucositis was confirmed by gastrointestinal symptoms (diarrhea, abdominal pain, and/or nausea/vomiting) and the plasma citrulline level. 
Laboratory methods

CRP was measured turbidimetrically using the Hitachi 917 analytic device and reagents of Roche Diagnostics. This method has a lower detection limit of $5 \mathrm{mg} / \mathrm{l}$. IL-8 was measured using the solid-phase, two-site chemiluminescent immunometric assay. IL- 8 was performed fully automated on the IMMULITE 1000. The lower detection limit of the assay is $5 \mathrm{ng} / \mathrm{l}$. Plasma concentrations of PCT were determined in duplicate by an enzyme-linked fluorescent immunoassay (VIDAS B.R.A.H.M.S PCT, provided by Biomérieux), and reported levels represent the mean of these values. The lower detection limit is $0.05 \mathrm{ng} / \mathrm{ml}$. sTREM-1 was measured using an ELISA assay. The plasma samples were diluted 4 times. The lower detection level is $7 \mathrm{pg} / \mathrm{ml}$. sTREM-1 determinations below the detection limit are shown in the figures as $7 \mathrm{pg} / \mathrm{ml}$.

Statistical analysis

Descriptive statistics were reported in terms of absolute frequencies and percentages. Distribution of data regarding febrile neutropenic episodes were described in terms of a median value and range, because of the nonnormal distribution of these values. Accordingly, comparison between groups was performed using the nonparametric Mann-Whitney $U$ test (for unpaired samples) or Wilcoxon signed-rank test (for paired samples). Associations were considered statistically significant with a $p$ value $<0.05$. Data were calculated for sensitivity and specificity, derived from receiver operating characteristics (ROC) curve. The commercial statistical software package used was Statistical Package for the Social Sciences 16.0 (SPSS, Chicago, IL).

\section{Results}

A total of 43 febrile neutropenic episodes in 29 patients were enrolled in the study. In 17 of the 43 febrile neutropenic episodes, plasma was also collected 24-48h after presentation with febrile neutropenia. Eleven patients were enrolled more than once. In 14 of the 43 febrile neutropenic episodes a bacterial infection (proven or suspected) was documented (32.6\%), by positive blood cultures (one Escherichia coli, one Klebsiella pneumoniae and three Streptococcus mitis), abnormal vital signs $(n=7)$, urinary tract infections $(n=2)$, radiographically confirmed pneumonia $(n=1)$, radiographically confirmed sinusitis $(n=1)$, or a panaritium $(n=1)$. The clinical data of the 43 febrile neutropenic episodes and 29 patients are shown in Table 1. No significant differences were found between the groups, although the type of cancer $(p=0.062)$ probably would have been significant if the group of patients had been larger.

The influence of mucositis on the levels of CRP, IL-8, PCT and sTREM-1 was studied in a total of 26 episodes in eight patients in the presence and in the absence of mucositis. Five of the eight patients were female $(63 \%)$. The age of the included patients ranged from one to 15 years. Four patients developed fever during the presence of mucositis. None of the patients with mucositis had a bacterial infection. The median leukocyte count, ANC, and the plasma citrulline level in the presence and absence of mucositis are shown in Table 2.

Comparison of variables between patients with and without bacterial infection Figure 1 shows the inflammatory markers in infected and noninfected patients at presentation
Table 1 Characteristics of the febrile neutropenia study population

$A N C$ absolute neutrophil count

\begin{tabular}{|c|c|c|c|}
\hline & Bacterial infection & No bacterial infection & $P$ value \\
\hline Number & 14 & 29 & \\
\hline \multicolumn{4}{|l|}{ Sex-no. $(\%)$} \\
\hline Female & $9(64 \%)$ & $12(41 \%)$ & \\
\hline Male & $5(36 \%)$ & $17(59 \%)$ & 0.164 \\
\hline \multicolumn{4}{|l|}{ Age-years } \\
\hline Median (interquartile range) & $8(6-13)$ & $8(6-12)$ & 0.845 \\
\hline \multicolumn{4}{|l|}{ Type of cancer-no. $(\%)$} \\
\hline Hematological malignancy & $11(79 \%)$ & $14(48 \%)$ & \\
\hline Solid tumor & $3(21 \%)$ & $15(52 \%)$ & 0.062 \\
\hline \multicolumn{4}{|l|}{ Leukocytes at admission $\left(\times 10^{9} / \mathrm{L}\right)$} \\
\hline Median (range) & $0.25(0.00-1.6)$ & $0.4(0.01-4.2)$ & 0.252 \\
\hline \multicolumn{4}{|l|}{ ANC at admission $\left(\times 10^{9} / \mathrm{L}\right)$} \\
\hline Median (range) & $0.03(0.02-0.04)$ & $0.06(0.00-0.67)$ & 0.381 \\
\hline
\end{tabular}


Table 2 Characteristics of the mucositis study population

\begin{tabular}{llll}
\hline & No mucositis & Mucositis & $P$ value \\
\hline $\begin{array}{l}\text { Number } \\
\text { Leukocyte count }\left(\times 10^{9} / \mathrm{L}\right)\end{array}$ & 26 & \\
$\begin{array}{l}\text { Median (range) } \\
\text { ANC }\left(\times 10^{9} / \mathrm{L}\right)^{\mathrm{a}}\end{array}$ & $3.7(0.6-24.6)$ & $0.55(0.2-6.3)$ & 0.001 \\
$\begin{array}{c}\text { Median (range) } \\
\text { Citrulline ( } \mu \mathrm{mol} / \mathrm{L}) \\
\text { Median (range) }\end{array}$ & $1.6(0.2-3.2)$ & $0.05(0.05-5.74)$ & 0.075 \\
\hline
\end{tabular}

$A N C$ absolute neutrophil count

${ }^{a}$ The ANC was often too low to measure (in these cases they were regarded as $0.05 \times 10^{9} / \mathrm{L}$ ), or not measured at all during mucositis

with febrile neutropenia. Median IL-8 and PCT levels were significantly higher in patients with bacterial infection compared with patients without bacterial infection (318.5 vs $55 \mathrm{ng} / 1, p=0.002 ; 0.81 \mathrm{vs} 0.10 \mathrm{ng} / \mathrm{ml}, p=0.001$, respectively), at presentation with febrile neutropenia. Median CRP levels did not differ significantly ( $64 \mathrm{vs} 32 \mathrm{mg} / \mathrm{l}, p=0.183$ ). sTREM1 levels were below the detection limit in 33 patients, and therefore excluded from further analyses.

Twenty-four to forty-eight hours after presentation with febrile neutropenia, mean PCT levels were significantly elevated in patients with bacterial infection compared with patients without bacterial infection $(2.01$ vs $0.22 \mathrm{ng} / \mathrm{ml}$, $p=0.047)$. At this time point, no significant differences were documented in median CRP and IL-8 levels between patients with and without bacterial infection.
ROC curves were generated for CRP, IL-8, and PCT at admission with febrile neutropenia (Fig. 2). The area under the curve demonstrated good individual discriminatory power for IL- 8 and PCT $(0.810,95 \%$ CI $0.656-0.965 ; 0.769,95 \%$ CI $0.612-0.925$, respectively). CRP demonstrated poor discriminatory power $(0.596,95 \%$ CI $0.388-0.803)$.

Table 3 shows the sensitivity and specificity for CRP, IL-8, and PCT at presentation with febrile neutropenia and 24- $48 \mathrm{~h}$ later, at cut-off values of $40 \mathrm{mg} / \mathrm{l}$ for CRP, $60 \mathrm{ng} / \mathrm{l}$ for IL-8, and $0.25 \mathrm{ng} / \mathrm{ml}$ for PCT. These cut-off values were chosen based on the best sensitivity and specificity (data not shown), and according to the literature. IL-8 showed the highest sensitivity (92\%) compared with PCT and CRP (sensitivity $79 \%$ and $69 \%$, respectively). The analyses were continued by constructing combinations between CRP, IL-8, and PCT, and evaluating their values in the distinction between bacterial infection and other causes of fever. IL- 8 in combination with PCT documented the most sensitive and specific results. The sensitivity for this combination was $100 \%$, whereas specificity was $52 \%$. Table 4 shows the $p$ values, sensitivity and specificity of the combinations of the biomarkers.

Comparison of variables in the presence and absence of gastrointestinal mucositis To study whether the markers could be useful as predictors for bacterial infection during chemotherapy-induced mucositis, we examined the behavior of the various markers during gastrointestinal mucositis. Mucositis did not cause considerable changes in PCT levels and CRP levels ( $0.06 \mathrm{ng} / \mathrm{ml}$ vs $0.06 \mathrm{ng} / \mathrm{ml}, p=0.709 ; 8 \mathrm{mg} / \mathrm{l}$ vs
Fig. 1 CRP, IL-8, PCT, and sTREM-1 at presentation with febrile neutropenia in patients with and without bacterial infection. The horizontal lines represent the median. sTREM-1 is shown by $\log 10$ at the $y$-axis, because of the widespread values
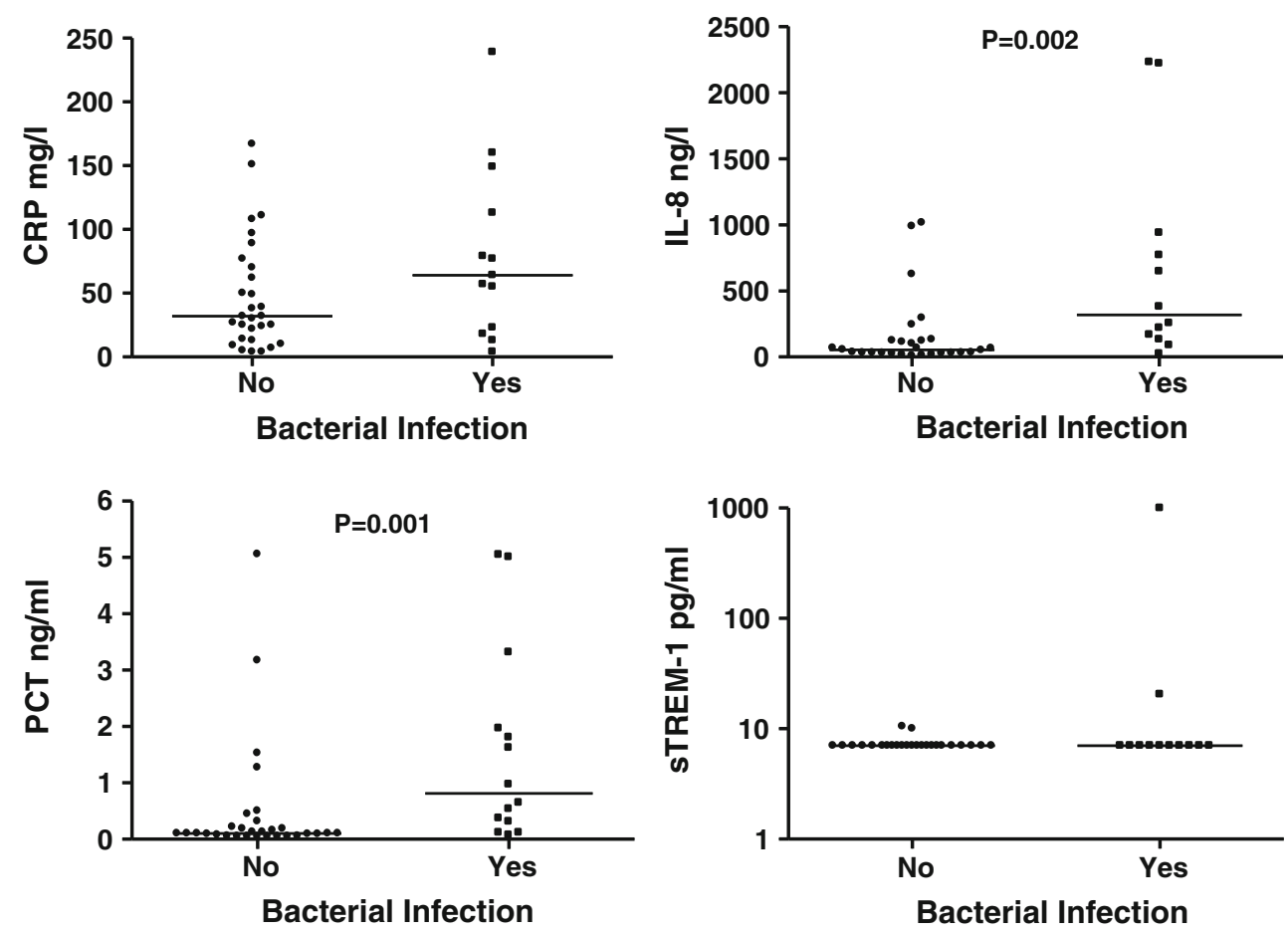


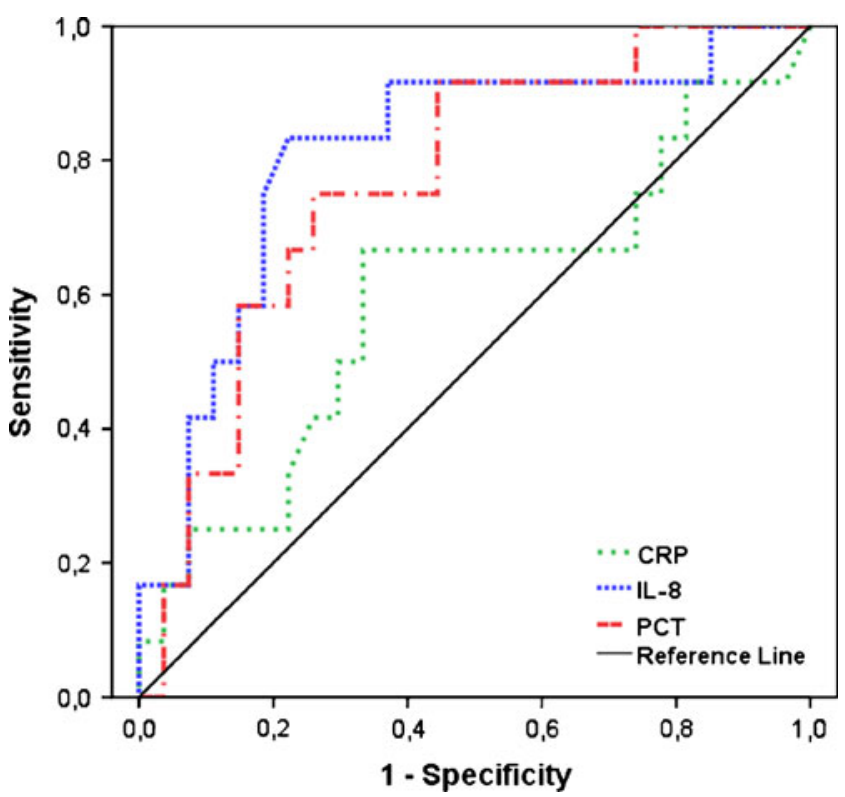

Fig. 2 ROC-curve for CRP, IL-8, and PCT at presentation with febrile neutropenia

$5 \mathrm{mg} / \mathrm{l}, p=0.182$, respectively). In contrast, the levels of IL8 were significantly increased during mucositis $(52.4 \mathrm{ng} / \mathrm{l} \mathrm{vs}$ $5.17 \mathrm{ng} / \mathrm{l}, p<0.01)$. sTREM-1 levels were below the detection limit in 35 cases, and therefore excluded from analysis. Figure 3 shows CRP, IL-8, PCT, and sTREM-1 in patients with and without mucositis.

\section{Discussion}

In pediatric oncology patients with febrile neutropenia, there is a need for markers that can determine which patients are at high risk for bacterial infection and need antibiotics, and in whom antibiotics can be withheld. In this study we showed that CRP, which is widely used as detector for bacterial infections, is actually a poor discriminatory marker. IL-8 is more useful as marker for the early detection of bacterial infections, and IL-8 in combination with clinical parameters or PCT might be even more useful.
Gastrointestinal mucositis alone does not affect PCT levels, in contrast to IL-8 levels, and therefore, PCT might be more useful for the detection of bacterial infections during mucositis than IL-8. Furthermore, we suggest the additional use of PCT to define patients in whom antibiotics can be stopped early.

Many studies have examined biochemical markers for the detection of bacterial infections. Most studies have been performed in nonneutropenic, adult patients. Nevertheless, a number of studies have suggested that neutropenic pediatric patients can produce a sufficient inflammatory response to release CRP, IL-8, and PCT [7, 17, 30-32]. These results are in line with our findings. Whether neutropenic children or adults can produce a sufficient release of sTREM-1 in response to infection has by our knowledge not yet been studied.

CRP, which is commonly used in practice, was shown in this study to be a poor tool for distinguishing bacterial infection from other causes of fever, given its low sensitivity and specificity (69\% and 62\%, respectively). According to our results, IL-8 is the best marker for the early detection of bacterial infection. The sensitivity at admission with febrile neutropenia was shown to be respectably high (92\%). High sensitivity is an essential quality for a marker in order to be valuable in the selection of patients in whom antibiotics can safely be withheld. In the case of IL-8, only one patient with a bacterial infection had IL-8 levels below the cut-off value of $60 \mathrm{ng} / \mathrm{l}$. This patient was classified as having a bacterial infection because of clinical signs of sepsis (tachypnea and tachycardia). Therefore, combining IL-8 and clinical parameters (blood pressure, heart rate, and respiratory rate) could allow an increase in the sensitivity up to $100 \%$, as stated by Oude Nijhuis et al. [4]. Our findings are comparable to those of others [31,33].

Fleischhack and her colleagues [31] suggested that PCT may be a more useful diagnostic inflammatory parameter than CRP, IL-6, IL-8, sIL-2, and sTNFRII in neutropenic pediatric cancer patients, but they chose Gram-negative bacteraemia and fever of unknown origin as primary endpoints, where we wanted to find markers to distinguish bacterial infection from other causes of fever. In our study, the sensitivity of PCT at presentation with febrile neutropenia

Table 3 Sensitivity and specificity for CRP, IL-8, and PCT at presentation of febrile neutropenia $(t=0)$ and after 24-48 h $(t=24-48)$ to distinguish bacterial infection from other causes of fever

\begin{tabular}{lllcccc}
\hline & AUC $(95 \% \mathrm{CI})$ & Cut-off & Sensitivity $(t=0)$ & Specificity $(t=0)$ & Sensitivity $(t=24-48)$ & Specificity $(t=24-48)$ \\
\hline CRP & $0.609(0.392-0.826)$ & $40 \mathrm{mg} / 1$ & $69 \%$ & $62 \%$ & $100 \%$ & $42 \%$ \\
IL-8 & $0.807(0.644-0.970)$ & $60 \mathrm{ng} / 1$ & $92 \%$ & $54 \%$ & $100 \%$ & $57 \%$ \\
PCT & $0.840(0.710-0.970)$ & $0.25 \mathrm{ng} / \mathrm{ml}$ & $79 \%$ & $77 \%$ & $100 \%$ & $53 \%$ \\
\hline
\end{tabular}

$A U C$ area under the curve; $C I$ confidence interval 
Table 4 Comparison of combinations of IL-8, PCT, and CRP, and their sensitivity and specificity in distinguishing bacterial infection from other causes of fever at presentation with febrile neutropenia

\begin{tabular}{|c|c|c|c|c|c|}
\hline & Bacterial infection & No bacterial infection & $P$ value & Sensitivity & Specificity \\
\hline IL- $8>60$ and/or PCT $>0.25$ & $14 / 14$ & $14 / 29$ & 0.001 & $100 \%$ & $52 \%$ \\
\hline IL- $8>60$ and/or $C R P>40$ & $12 / 13$ & $17 / 28$ & 0.041 & $92 \%$ & $39 \%$ \\
\hline PCT $>0.25$ and/or $\mathrm{CRP}>40$ & $13 / 14$ & $15 / 29$ & 0.016 & $93 \%$ & $48 \%$ \\
\hline
\end{tabular}

was only $79 \%$. Therefore, PCT alone might not be useful in the early detection of infection. However, 24-48 h after presentation with febrile neutropenia, PCT is significantly elevated in patients with a bacterial infection. Thus, PCT is a relatively late marker and might be of value in identifying patients in whom antibiotics can be stopped early. This is in line with data suggesting that serial measurements of PCT levels might help guiding antibiotic treatment in septic, nonneutropenic adult patients [23, 34].

sTREM-1 has recently been suggested as a marker for bacterial infection [24, 26, 28], but had not been studied before in neutropenic patients. It is known that sTREM-1 is expressed mainly on neutrophils and monocytes, when triggered by bacteria. We studied whether there is an increase of sTREM-1 levels during bacterial infections in neutropenic patients, who might have enough monocytes to produce measurable sTREM-1 levels. However, our results showed that sTREM-1 is not usable as a marker in this patient population. In our study only one patient had high sTREM-1 levels $(997 \mathrm{pg} / \mathrm{ml})$. This patient in fact did have a normal number of monocytes, which was $0.64 \times 10^{9} / 1$ (normal levels, $0.3-1.3 \times 10^{9} / 1$ ), while the ANC was no more than $0.04 \times 10^{9} / 1$. In all other patients both the number of monocytes and the ANC were low (data not shown), which could explain the low sTREM-1 levels in the infected patients.

The best combination of markers for identifying bacterial infections in febrile neutropenic patients appears to be IL-8 and PCT. This combination results in a sensitivity of $100 \%$ in our patient population, and therefore seems to be the optimal combination for the early detection of bacterial infection.

In addition, we examined the various markers during gastrointestinal mucositis, since mucositis is a commonly seen phenomenon in pediatric oncology patients, causing fever, but not requiring antibiotic treatment. As we have shown before [29], IL-8 was elevated during mucositis, even though patients did not suffer from a bacterial infection. It thus seems that IL- 8 is not useful as a marker for bacterial infection in patients with mucositis. Our results
Fig. 3 CRP, IL-8, PCT, and STREM-1 in the presence and in the absence of mucositis. The horizontal lines represent the median. The markers are shown by $\log 10$ at the $y$-axis, because of the widespread values
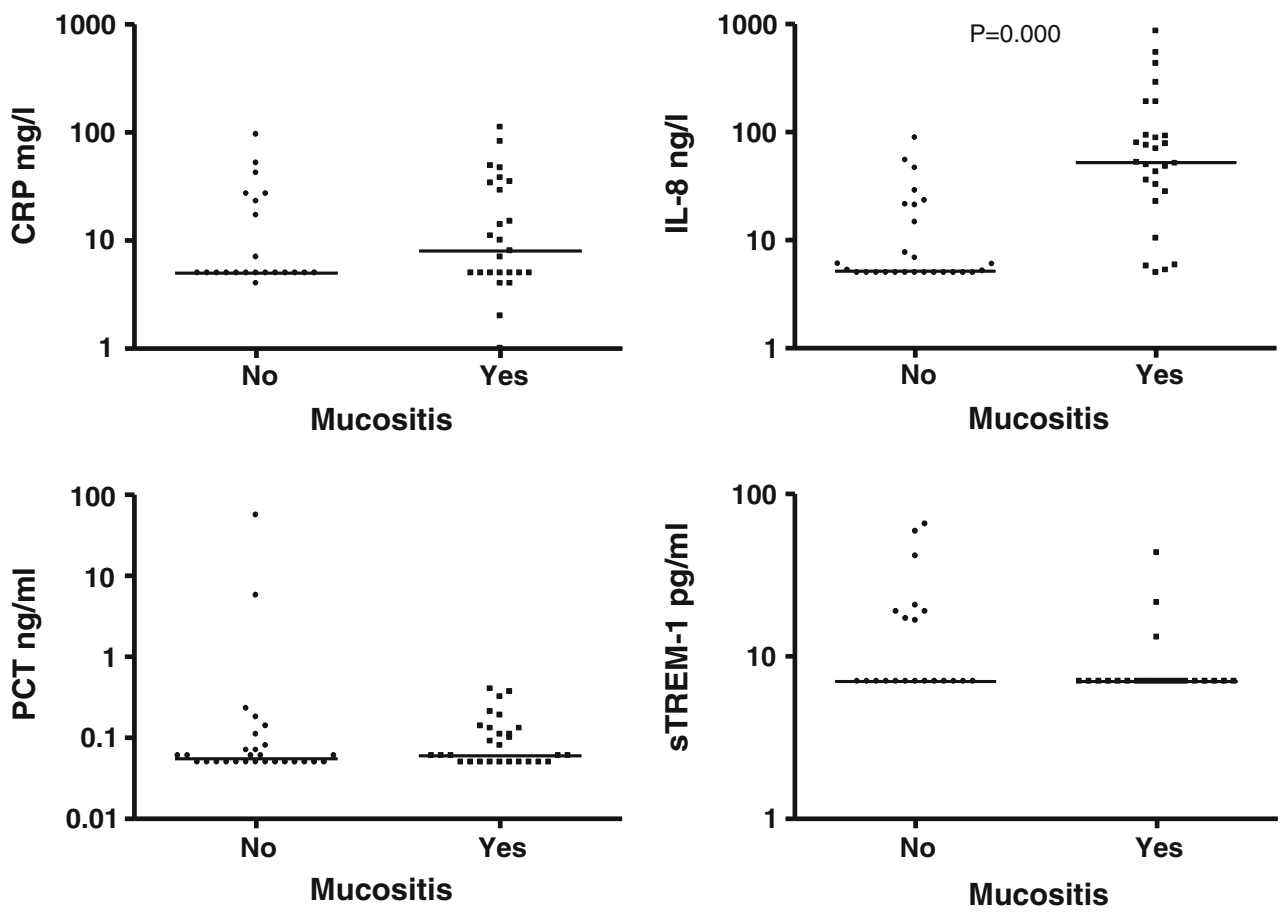
are in line with data on adult bone marrow transplant patients [35]. In contrast, other authors showed no increase of IL-8 in response to mucositis $[31,36]$. Our results further showed that CRP and PCT levels are not significantly influenced by mucositis. This is comparable to the results of Fleischhack et al. [31]. On the other hand, there are some studies that have documented a rise of CRP levels in response to mucositis [35, 37]. Future studies have to elucidate whether PCT is usable as marker for bacterial infection during chemotherapy-induced gastrointestinal mucositis in patients with a bacterial infection during mucositis.

sTREM-1 had not yet been studied as a marker for bacterial infection during mucositis. However, patients develop chemotherapy-induced gastrointestinal mucositis in the same period as they develop chemotherapy-induced neutropenia. In line with the results of neutropenic fever, we showed that sTREM-1 is not elevated during mucositis.

One might argue that the definition we used to ascertain mucositis is questionable. The golden standard for measuring gastrointestinal mucositis actually is a small intestine biopsy. However, this method is not feasible in (pediatric) patients, especially during neutropenia, which most often accompanies mucositis. Other well-known methods for the detection of mucositis are the NCI Common Terminology Criteria for Adverse Events Score and the Daily Gut Score. However, these methods both include fecal incontinence, which occurs physiologically in young children and in older ill children as a sign of regression. Therefore, we used a less invasive, good alternative method for the detection of gastrointestinal mucositis in children, which consists of the combination of presence of gastrointestinal symptoms, such as diarrhea, abdominal pain, and/or nausea/vomiting (as is used by the NCI and the Daily Gut Score) and the plasma citrulline level. Citrulline is a marker for enterocytic cell loss, and has been shown to be a good clinical biomarker for measuring and monitoring gastrointestinal mucositis $[29,38]$.

Of course, the number of patients in this study was small. Larger prospective studies are needed to establish the value of IL-8 in determining patients in whom antibiotics can be withheld. In fact, we are currently studying a risk model for febrile neutropenic pediatric patients, based on IL-8 and clinical parameters, in a multicenter setting, as was proposed by Oude Nijhuis et al. [4].

In conclusion, IL-8 seems to be the best marker for the early detection of bacterial infections in pediatric oncology patients with febrile neutropenia. In combination with clinical parameters, the sensitivity might be able to reach even $100 \%$, therefore this combination seems to be the perfect tool in defining which febrile neutropenic patients are at high risk of bacterial infection and need antibiotics, and in whom antibiotics can be withheld. PCT might be of additive value in identifying patients in whom antibiotics can be stopped early, and during gastrointestinal mucositis.

Acknowledgments We would like to thank Siemens for supplying the kits for the IL-8 measurements, Biomérieux for supplying the kits for the PCT measurements, and IQproducts for supplying the kits for the sTREM-1 measurements.

Financial support No support

Potential Conflicts of interest All authors declare no conflict of interest.

Open Access This article is distributed under the terms of the Creative Commons Attribution Noncommercial License which permits any noncommercial use, distribution, and reproduction in any medium, provided the original author(s) and source are credited.

\section{References}

1. Bodey GP, Buckley M, Sathe YS, Freireich EJ (1966) Quantitative relationships between circulating leukocytes and infection in patients with acute leukemia. Ann Intern Med 64:328-340

2. Hann I, Viscoli C, Paesmans M, Gaya H, Glauser M (1997) A comparison of outcome from febrile neutropenic episodes in children compared with adults: results from four EORTC studies. International Antimicrobial Therapy Cooperative Group (IATCG) of the European Organization for Research and Treatment of Cancer (EORTC). Br J Haematol 99:580-588

3. Hughes WT, Armstrong D, Bodey GP et al (2002) 2002 guidelines for the use of antimicrobial agents in neutropenic patients with cancer. Clin Infect Dis 34:730-751

4. Oude Nijhuis C, Kamps WA, Daenen SM et al (2005) Feasibility of withholding antibiotics in selected febrile neutropenic cancer patients. J Clin Oncol 23:7437-7444

5. Hodgson-Viden H, Grundy PE, Robinson JL (2005) Early discontinuation of intravenous antimicrobial therapy in pediatric oncology patients with febrile neutropenia. BMC Pediatr 5:10

6. Castagnola E, Fontana V, Caviglia I et al (2007) A prospective study on the epidemiology of febrile episodes during chemotherapyinduced neutropenia in children with cancer or after hemopoietic stem cell transplantation. Clin Infect Dis 45:1296-1304

7. Santolaya ME, Alvarez AM, Becker A et al (2001) Prospective, multicenter evaluation of risk factors associated with invasive bacterial infection in children with cancer, neutropenia, and fever. J Clin Oncol 19:3415-3421

8. Ammann RA, Hirt A, Luthy AR, Aebi C (2003) Identification of children presenting with fever in chemotherapy-induced neutropenia at low risk for severe bacterial infection. Med Pediatr Oncol 41:436-443

9. Klaassen RJ, Goodman TR, Pham B, Doyle JJ (2000) "Low-risk" prediction rule for pediatric oncology patients presenting with fever and neutropenia. J Clin Oncol 18:1012-1019

10. te Poele EM, Tissing WJ, Kamps WA, de Bont ES (2009) Risk assessment in fever and neutropenia in children with cancer: What did we learn? Crit Rev Oncol Hematol 72:45-55

11. de Bont ES, Vellenga E, Swaanenburg JC, Fidler V, Visser-van Brummen PJ, Kamps WA (1999) Plasma IL-8 and IL-6 levels can be used to define a group with low risk of septicaemia among cancer patients with fever and neutropenia. $\mathrm{Br} \mathrm{J}$ Haematol 107:375-380 
12. Ammann RA, Bodmer N, Hirt A et al (2010) Predicting adverse events in children with fever and chemotherapy-induced neutropenia: the prospective multicenter SPOG 2003 FN Study. J Clin Oncol 28(12):2008-2014

13. Heney D, Lewis IJ, Evans SW, Banks R, Bailey CC, Whicher JT (1992) Interleukin-6 and its relationship to C-reactive protein and fever in children with febrile neutropenia. J Infect Dis 165:886-890

14. Katz JA, Mustafa MM, Bash RO, Cash JV, Buchanan GR (1992) Value of C-reactive protein determination in the initial diagnostic evaluation of the febrile, neutropenic child with cancer. Pediatr Infect Dis J 11:708-712

15. Prat C, Sancho JM, Dominguez J et al (2008) Evaluation of procalcitonin, neopterin, C-reactive protein, IL-6 and IL-8 as a diagnostic marker of infection in patients with febrile neutropenia. Leuk Lymphoma 49:1752-1761

16. Mukaida N (2000) Interleukin-8: an expanding universe beyond neutrophil chemotaxis and activation. Int J Hematol 72:391-398

17. Stryjewski GR, Nylen ES, Bell MJ et al (2005) Interleukin-6, interleukin-8, and a rapid and sensitive assay for calcitonin precursors for the determination of bacterial sepsis in febrile neutropenic children. Pediatr Crit Care Med 6:129-135

18. Lindemann A, Tamm I, Tanodi K, Mertelsmann R (1995) Interleukin-8 serum levels for early detection of infectious episodes in neutropenic patients. J Infect Dis 172:610

19. Assicot M, Gendrel D, Carsin H, Raymond J, Guilbaud J, Bohuon C (1993) High serum procalcitonin concentrations in patients with sepsis and infection. Lancet 341:515-518

20. Dandona P, Nix D, Wilson MF et al (1994) Procalcitonin increase after endotoxin injection in normal subjects. J Clin Endocrinol Metab 79:1605-1608

21. al Nawas B, Shah PM (1996) Procalcitonin in patients with and without immunosuppression and sepsis. Infection 24:434-436

22. Hatzistilianou M, Rekliti A, Athanassiadou F, Catriu D (2009) Procalcitonin as an early marker of bacterial infection in neutropenic febrile children with acute lymphoblastic leukemia. Inflamm Res 59:229-347

23. Hochreiter M, Kohler T, Schweiger AM et al (2009) Procalcitonin to guide duration of antibiotic therapy in intensive care patients: a randomized prospective controlled trial. Crit Care 13:R83

24. Bouchon A, Dietrich J, Colonna M (2000) Cutting edge: inflammatory responses can be triggered by TREM-1, a novel receptor expressed on neutrophils and monocytes. J Immunol 164:4991-4995

25. Gibot S, Le Renard PE, Bollaert PE et al (2005) Surface triggering receptor expressed on myeloid cells 1 expression patterns in septic shock. Intensive Care Med 31:594-597

26. Rivera-Chavez FA, Minei JP (2009) Soluble triggering receptor expressed on myeloid cells-1 is an early marker of infection in the surgical intensive care unit. Surg Infect (Larchmt) 10(5):435-439
27. Bopp C, Hofer S, Bouchon A, Zimmermann JB, Martin E, Weigand MA (2009) Soluble TREM-1 is not suitable for distinguishing between systemic inflammatory response syndrome and sepsis survivors and nonsurvivors in the early stage of acute inflammation. Eur J Anaesthesiol 26:504-507

28. Phua J, Koay ES, Zhang D, Lee KH (2008) How well do serum sTREM-1 measurements prognosticate in septic shock? Anaesth Intensive Care 36:654-658

29. van Vliet MJ, Tissing WJ, Rings EH et al (2009) Citrulline as a marker for chemotherapy induced mucosal barrier injury in pediatric patients. Pediatr Blood Cancer 53:1188-1194

30. Kern WV, Heiss M, Steinbach G (2001) Prediction of gramnegative bacteremia in patients with cancer and febrile neutropenia by means of interleukin- 8 levels in serum: targeting empirical monotherapy versus combination therapy. Clin Infect Dis 32:832835

31. Fleischhack G, Kambeck I, Cipic D, Hasan C, Bode U (2000) Procalcitonin in paediatric cancer patients: its diagnostic relevance is superior to that of $\mathrm{C}$-reactive protein, interleukin 6 , interleukin 8 , soluble interleukin 2 receptor and soluble tumour necrosis factor receptor II. Br J Haematol 111:1093-1102

32. Secmeer G, Devrim I, Kara A et al (2007) Role of procalcitonin and CRP in differentiating a stable from a deteriorating clinical course in pediatric febrile neutropenia. J Pediatr Hematol Oncol 29:107-111

33. Lehrnbecher T, Venzon D, de Haas M, Chanock SJ, Kuhl J (1999) Assessment of measuring circulating levels of interleukin-6, interleukin-8, C-reactive protein, soluble Fc gamma receptor type III, and mannose-binding protein in febrile children with cancer and neutropenia. Clin Infect Dis 29:414-419

34. Nobre V, Harbarth S, Graf JD, Rohner P, Pugin J (2008) Use of procalcitonin to shorten antibiotic treatment duration in septic patients: a randomized trial. Am J Respir Crit Care Med 177:498505

35. Blijlevens NM, Donnelly JP, DePauw BE (2005) Inflammatory response to mucosal barrier injury after myeloablative therapy in allogeneic stem cell transplant recipients. Bone Marrow Transplant 36:703-707

36. Stokman MA, Oude Nijhuis CS, Spijkervet FK et al (2006) The role of oral mucositis on the systemic inflammation parameter IL-8 in febrile neutropenic cancer patients. Cancer Invest 24:479-483

37. Ki Y, Kim W, Nam J, Kim D, Park D, Kim D (2009) C-reactive protein levels and radiation-induced mucositis in patients with head-and-neck cancer. Int J Radiat Oncol Biol Phys 75:393-398

38. Herbers AH, Feuth T, Donnelly JP, Blijlevens NM (2010) Citrulline-based assessment score: first choice for measuring and monitoring intestinal failure after high-dose chemotherapy. Ann Oncol 21(8):1706-1711 